\title{
Aluminum Chloride-Induced Oxidative Damage to Serum and Combined Intervention of Ascorbic Acids and Massularia Acuminata On Selected Markers Of In Vivo Antioxidant Enzymes in Wistar Rats
}

\author{
BAKARE1, * Oluwafemi Shittu1, Adedugbe, Omowunmi Funke², Owoloye Afolabi ${ }^{3}$. \\ ${ }^{1}$ Biochemistry Department, Faculty of Science, Adekunle Ajasin University, Akungba Akoko, Ondo State, \\ Nigeria. \\ ${ }^{2}$ Chemical Science Department, College of Natural and Applied Science, Achiever University, Owo, Ondo \\ State, Nigeria \\ ${ }^{3}$ Animal and Environmental Biology Department, Faculty of Science, Adekunle Ajasin University, Akungba \\ Akoko, Ondo State, Nigeria
}

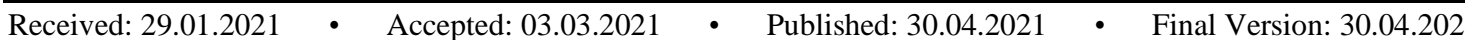

\begin{abstract}
This study evaluates the synergistic antioxidants effects of extracts of Massularia acuminata and ascorbic acid in aluminum chloride-treated oxidative stress in wistar albino rats with a view to investigate the preventive potential of co-administration of Massularia acuminata and ascorbic acids. The in vivo antioxidant properties of the extract were evaluated using in vivo catalase activity, superoxide dismutase activity and thiobarbituric acid reactive substances assay by standard methods via spectrophotometry. The in vivo studies were carried out on rats, grouped majorly into positive control, negative control and the treated groups. The positive control group was administered with normal saline (distilled water) orally, while the negative control group was orally induced with the toxicant (aluminium chloride). The treated group was orally administered with the extract after toxicant administration. Ascorbic acid was used as standard antioxidant in the study. The effects on enzymatic antioxidants and lipid indices were evaluated. Forty healthy Wistar rats sub-grouped into ten (10) groups were induced with aluminum chloride. Some rats were treated with ascorbic acid which is a well-known antioxidant, while others were treated with various extracts of Massularia acuminata (Pako Ijebu) at various doses. The experiment is designed as follows: in Group 1, animals were used as control group. Animals in Group 2 were the toxicant-treated groups administered with $\mathrm{AlCl}_{3}(34 \mathrm{mg} / \mathrm{kg}$ body weight). Ascorbic acid treated groups are the standard control (group 3) administered with $200 \mathrm{mg} / \mathrm{kg}$ body weight. Animals in Group 4 were co-treated with $\mathrm{AlCl}_{3}$ and Ascorbic acid ( $34 \mathrm{mg} / \mathrm{kg}$ aluminum chloride and $200 \mathrm{mg} / \mathrm{kg}$ body weight of ascorbic acid). Animals in group 5 were co-administered with ethanolic extract (50 mg/kg body weight) of Massularia acuminata and $\mathrm{AlCl}_{3}(34 \mathrm{mg} / \mathrm{kg}$ body weight), respectively. Animals in group 6 were also co-treated and administered with ethanolic extract of Massularia acuminate $(100 \mathrm{mg} / \mathrm{kg}$ body weight) and $\mathrm{AlCl}_{3}$, respectively. Experimental animals in group 7 were equally co-administered with methanolic extract of Massularia acuminate $\left(50 \mathrm{mg} / \mathrm{kg}\right.$ body weight) and $\mathrm{AlCl}_{3}$, respectively. Animals in group 8 were co-administered with methanolic extract of Massularia acuminate (100 $\mathrm{mg} / \mathrm{kg}$ body weight) and $\mathrm{AlCl}_{3}$, respectively. Group 9 animals were co-administered with butanolic extracts of Massularia acuminata $\left(50 \mathrm{mg} / \mathrm{kg}\right.$ body weight) and $\mathrm{AlCl}_{3}$, respectively. Group 10 experimental animals were also co-administered with butanolic extract of Massularia acuminate $(100 \mathrm{mg} / \mathrm{kg}$ body weight $)$ and $\mathrm{AlCl}_{3}$, respectively. At the end of the experiment, the animal was
\end{abstract}

\footnotetext{
* Corresponding Author: bakfemsonline@gmail.com
} 
sacrificed after three weeks by cervical dislocation after they were immobilized using chloroform. Results show that ethanolic and methanolic extracts of Massularia acuminata contain antioxidant properties. Both doses of ethanolic extract dose $(50 \mathrm{mg} / \mathrm{kg}$ and $100 \mathrm{mg} / \mathrm{kg}$ body weight $)$ group of methanol extract also reduced the level of MDA but not as ascorbic acid group. Both doses of methanolic extract of Masssularia acuminata act contrariwise from other extracts in that they show the highest level of malonaldehyde even more than $\mathrm{AlCl}_{3}$. The results of superoxide dismutase (SOD) assay test in this study show that the control group, ascorbic acid combined with $\mathrm{AlCl}_{3}$ group, 50 $\mathrm{mg} / \mathrm{kg}$ body weight of ethanolic extract. Both doses of methanolic extract groups have the same comparative value of SOD. The group treated with toxicant (aluminum chloride) and ascorbic group has similar relative value. The group treated with $50 \mathrm{mg} / \mathrm{kg}$ body weight of butanolic extract shows the highest value of superoxide dismutase activity that follow closely by $100 \mathrm{mg} / \mathrm{kg}$ of ethanolic extract group. The study concluded that Massularia acuminata, like ascorbic acids, can induced antioxidant enzymes such as SOD and CAT in aluminium chloride-induced oxidative stressed rats. It may therefore be used to protect the body against any pathological attacks from free radical and oxidative insults.

Keywords: Oxidative stress, antioxidant, Massularia acuminata, Superoxide dismutase (SOD), Catalase (CAT), lipid peroxidation, ascorbic acid, serum

\section{INTRODUCTION}

Aluminum appears to be the third most plentiful element on the surface of earth's crust, approximately $8 \%$ of the entire inorganic constituents or ingredients. It is often obtained in complex with oxygen, silicon, fluorine, and other constituents in the nature and pose a substantial harmful threat to man (Verstraeten et al., 2008). Aluminum is randomly allotted in the surrounding world, often used in every daily human's life, and often speed up human accessibility and exposure to it, thereby making human beings to be vulnerable to its exposure (Kumar and Gill, 2009). Aluminium has been extensively use as constituent of cooking utensils and practices of medicines such like some antacid, phosphate binders, buffered aspirins, vaccines, antiperspirants, allergen injection (Exley, 1998), deodorants as well as toothpaste (Abbasali et al., 2005). Healthy adults take in about 3-5 mg dose of aluminum daily in combination with their diets and varying quantity from drinkable (beverage) reckoning on their prevailing circumstances of water treatments and purification. This ingredient inflicts a negative threat to man's wellness (Osinska et al., 2004). Human exposure to aluminum in drinking water and vulnerability may be a major external contributory key reason for the evolution of Alzheimer disease (AD) (Yokel, 2000). It arrives the human body through airways. After assimilation, nearly all aluminum is channeled by the bloodline to various body organs. Bones, muscles, and lungs contain the highest aluminum contents in normal human beings. Aluminum conglomeration in the excretory organ boosts the devolution of renal cells, causing nephron damages (Mansour et al., 2006), as it enhances renal failure with concomitant systemic associated toxicity (Mahieu et al., 2005). Moreover, aluminum conglomerates in the liver sometimes and often ends up in acholia (Osinska et al., 2004). Its toxicological effects on humans includes brain disorder, bone malady, anemia, and skeletal system disease. These harmful consequences and threats of aluminum may be due to the propagation of reactive oxygen radicals (El-Demerdash, 2007), which eventually leads to oxidative deterioration of cellular biomolecules which ascorbic acid antagonize it actions (El- Demerdash 2004; Mansour et al., 2006). Aluminum ions change the properties and structure of cellular biomembranes, suppress many enzymes like alkaline phosphatase, acetyl cholinesterase, and adenyl cyclase (Qitu et al., 2002). Incompatible interactions between aluminum ions and other ingredients like calcium, magnesium, iron, silicon, phosphorus, copper, and zinc were observed in 
biological systems (Ward et al., 2001). Vitamin C is an indispensable micronutrient essential for conventional metabolic operation of the body. It is one of the essential antioxidants in biological fluid. Vitamin $\mathrm{C}$ is a cofactor for various enzymes essential for the biosynthesis of collagen, carnitine, and neurotransmitters. In addition, vitamin $\mathrm{C}$ is employed as an essential chemical compound for catecholamine biosynthesis, essentially in the transition of dopamine to norepinephrine catalyzed by dopamine monooxygenase. Many biochemical, clinical and epidemiological studies showed that vitamin $\mathrm{C}$ may be useful in preventing of chronic diseases, such as cardiovascular disease, cancer and cataract. The possible reasons for these benefits of vitamin $\mathrm{C}$ are the antioxidant mechanisms which can be the consequences of aluminum chloride insults by scavenging free radical species of both reactive oxygen groups (super oxide and hydro peroxyl) and reactive nitrogen group (nitrogen dioxide and peroxynitrite) (Northrop-Clewes and Thurnham, 2007). Vitamin $C$ may hinder free radical damage in the lungs and consequently help to defend essential biological processes from such toxicities. It hinders the toxic, mutagenic, and carcinogenic actions of environmental pollutants such as aluminum chloride by inducing liver detoxifying enzymes. Humans as well as primates have lost some of their ability to produce ascorbic acid because of the variation in gene writing for l-gulonolactone oxidase, an enzyme needed for the biogenesis of ascorbic acid through the glucuronic acid pathway. Therefore, ascorbic acid must be derived through diet (Carr and Frei, 1999). Alternatively, there is need to look into other natural occurring phytochemicals that may probably be used to combat the toxicity of aluminum chloride. This is what led to the antioxidants activities study of Massularia acuminata on aluminum chloride toxicity. Massularia acuminata from the family of Rubiacea popularly known as chewing stick (English), Pako Ijebu (Yoruba Western Nigeria), and Igbo (Igbo - Eastern Nigeria) grows up to $5 \mathrm{~m}$ high. The leaves of this plant are often large, stalkless, elliptic and acuminate. Its flowers are usually red and appear sometimes in January. The fruits are narrowly ovoid, beaked, and yellowish-white in colour about $5 \mathrm{~cm}$ long. The stems are used as chewing sticks in southern Nigeria. The leaves are used in Nigeria to poison fish and prevent mouth infections (Burkill, 1997). Investigations suggest that the leaf of Massularia acuminata possesse some antioxidant activities (Aladesanmi et al., 2007). The stem aqueous extract possesse antimicrobial activity especially against periodontal microbes (Taiwo et al., 1999). The leaf has been also implicated as an oral prophylactic and reported to play an important role in gingival health (Aderinokun et al., 1999). The pulped roots are claimed to be useful for enema for dysentery, aphrodisiac and anticancer. The fruit juice is also used as antibiotic as eye drop in Sierra Leone (Yakubu et al., 2008). It is also reported that the alkaloidal content of the plant extract has anti-inflammatory activity and is effective in preventing gingivitis and periodontitis (Rotimi et al., 1987). Similarly, the androgenic and gonadotropic effects as well as aphrodisiac activity of the stem extract of Massularia acuminata at the varied doses per kilogram body weight have also been reported in separate studies using male rats as model (Yakubu et al., 2008).

\subsection{ALUMINUM CHLORIDE}

Aluminum chloride $\left(\mathrm{AlCl}_{3}\right)$, often referred to as aluminum dichloride, is the principal element in complex of aluminum and chlorine with white colour. It is often contaminated with iron (III) chloride, giving rise to a yellow colour. It usually comes in different forms and the solid from has a much lower melting and boiling point. It is principally used in the production of aluminum metal, but to a large extent, it is consumed in other aspects of some chemical industries. Aluminum is also a trivalent cation that does not undergo redox changes and extensive experimental evidence demonstrates both, in vitro and in vivo, that high aluminium concentrations leads to oxidative stress. Oxidative stress can be defined as an imbalance between free radical biogenesis and the antioxidant 
defense system. Oxidative stress caused by aluminium is one of the main contributory factors to male reproductive disorders. Interruption of metal ion equilibrium may result in oxidative stress, a state where increased formation of reactive oxygen species (ROS) overpowers body antioxidant defense, leading to destruction of biomolecules and other effects (Jomova and Valko, 2011). In spite of the low oxygen contents that qualify the testicular microenvironment, testis remains susceptible to oxidative stress due to the abundance of highly unsaturated fatty acids (particularly 20:4 and 22:6) and the presence of potential ROS generating systems (Aitken et al., 2008). Although aluminum is a relatively low redox mineral, it can induce oxidative damage through multiple mechanisms. Excessive free radicals' biogenesis by aluminium may lead to damage in mitochondrial bioenergetics and may lead to the generation of oxidative stress as well as reproductive disorders (Kumar et al., 2009). Aluminium catalyze iron driven biological oxidation via the production of aluminum super oxide ion $\left(\mathrm{AlO}_{2}{ }^{*}\right)$ and behaves as a pro-oxidant by both inducing the formation of $\mathrm{H}_{2} \mathrm{O}_{2}$ and reducing $\mathrm{Fe}^{3+}$ to $\mathrm{Fe}^{2+}$ (Mahdi et al., 2006). Excessive production of ROS can lead to the damage of sperm associated with male fertility. ROS may cause defective sperm function because of lipid peroxidation of the polyunsaturated fatty acids in the head and mid-piece. It can alter sperm morphology resulting in decreased sperm motility and viability. Induced oxidative stress by aluminium leads to an increase in germ cell apoptosis and subsequent hypospermatogenesis and fall in intercellular ATP level which may decrease sperm motility (Turner et al., 2008).

\subsection{ASCORBIC ACID}

Ascorbic acid is involved in many physiological functions in living organisms. Its role in the synthesis of collagen in connective tissues is well known (Hacışevki, 2009; Arrigoni and De Tullio, 2002). The absence of wound healing and the failure of fractures to repair are classically recognized features of scurvy. These features are attributable to impaired collagen formation due to the deficiency in vitamin C. Ascorbic acid is a strong reducing agent and readily oxidizes reversibly to dehydroascorbic acid. Studies on the interactions of ascorbic acid with various chemicals and metal ions have indicated that ascorbic acid and its oxidation product dehydroascorbic acid, as well as its intermediate monodehydroascorbic acid free radical, may function as cycling redox couples in reactions involving electron transport and membrane electrochemical potentiation (Eryllmaz, 2014; Sauer et al, 2004). Research on the electron transport and redox coupling reactions has been the subject of numerous biochemical studies. For example, ascorbic acid has been shown to participate in many different neurochemical reactions involving electron transport. Neurons are known to use ascorbic acid for many different chemical and enzymatic reactions, including the synthesis of neurotransmitters and hormones (Sauer et al, 2004; Aguirre et al, 2008). Studies on the interactions of extracellular ascorbic acid with various plasma membrane proteins suggest that ascorbic acid may function as a neuromodulator (Sauer et al, 2004). In a variety of other functions, the role of ascorbic acid in cellular metabolism can be accounted for via its reducing properties to protect cellular components from oxidative damage. It acts as a scavenger for oxidizing free radicals and harmful oxygen-derived species, such as the hydroxyl radical, hydrogen peroxide, and singlet oxygen (Eryllmaz, 2014). Certain biochemical reactions are known to be stimulated by the prooxidant activity of ascorbic acid. The bactericidal and antiviral activity of ascorbic acid in aqueous solution is presumably attributable to its prooxidant properties (Eryllmaz, 2014). Monday et al. (2016) reported the protective ability of the combined supplementation of ascorbic acid and vitamin $\mathrm{E}$ with $200 \mathrm{mg} / \mathrm{kg}$ body weight on arsenic-induced reproductive toxicity (Mukhopadhyay et al., 2013; Banik et al., 2014). Equally, based on clinical and experimental trial from the literature search, a number of studies have been carried out especially in human to determine the protective effects of ascorbic 
acid supplementation and doses of (100-500 mg/day) have been tested on in vivo studies (Anderson et al., 1997). Therefore, based on this literature search and justification, the researchers decided to use a sub- lethal dose of $200 \mathrm{mg} / \mathrm{kg}$ body weight on the experimental rats to justify the protective effects of ascorbic acid on lipid peroxidation in healthy rats.

\subsection{Massularia acuminata}

Massularia acuminata, from the family Rubiacea, is often called 'chewing stick' in English. Pako Ijebu (Yoruba Western Nigeria), or Igbo (Igbo-Eastern Nigeria) is an average sized shrub that grows up to $5 \mathrm{~m}$ high. It is often located in the floor some closed forest of western African countries. The leaves of the plant are large and sometimes stalkless. The flowers are usually red and borne in short axillary cymes and appears around January. The fruits are narrowly ovoid, beaked, and yellowishwhite in colour. The stems are always applied as chewing sticks in southern Nigeria (Oni and Ojo, 2002). The mashed roots are affirmed to be used as enema for dysentery, aphrodisiac and anticancer. The fruit juice is used as antibiotic for eye drop in Sierra Leone (Gill, 1992; Yakubu et al., 2008; Aderinokun et al., 1999; Yakubu et al., 2008; Yakubu et al., 2011). There is still little information on the antioxidants effect of the plant extract on some Wistar male rats in spite of much research reports.

\section{MATERIALS AND METHODS}

\subsection{CHEMICALS AND REAGENTS}

Normal Saline, Ethanol, Phosphate Buffer, Chloroform, Trizol, Distilled water, Randox Malonaldehyde kit Product number: 424660), Randox Superoxide dismutase kit (Product number: 435212), Randox Catalase kit (Product number: 269477).

\section{METHODOLOGY}

\subsection{PLANT SAMPLE COLLECTION}

Fresh whole stem of Massularia acuminata with its flowers were obtained from its natural forestry habitat in Akungba-Akoko, Ondo State, Nigeria.

\subsection{PREPARATION OF Massularia acuminata EXTRACTS}

Fresh stem of Massularia acuminata were chopped into smaller sizes. The smaller chopped Massularia acuminata stems were dried in a well-ventilated room for 2-3 weeks and grounded into fine powder. The powder Massularia acuminata stem was then equally separated into three portions where they were soaked in ethanol, methanol, and butanol respectively for 72 hours. Using a muslin bag, the resulting solution was filtered after which the resulting extracts were concentrated with the aid of rotary evaporator. The concentrate was air-dried for few days.

\subsection{EXPERIMENTAL ANIMALS GROUPING AND DESIGN}

40 healthy Wistar rats of about 6-week old were obtained from the animal house of Animal and Environmental Biology Department at Adekunle Ajasin University, Akungba - Akoko, Nigeria. They were then randomized and allowed to acclimatize for one week in a standard cage and fed with standard pellets feed and water. All experiments involving animals were conducted in the Department of Biochemistry, animal house. 


\subsection{EXPERIMENTAL ANIMALS DESIGN}

Group 1 (Normal Control): This is also called the control group. The animals in this group were not induced with aluminum chloride, nor were they treated with standard drug (ascorbic acid) or Massularia acuminata.

Group 2 (Toxicant Control): This group consisted of animals that were induced with $34 \mathrm{mg} / \mathrm{kg}$ body weight aluminum chloride but not with ascorbic acid.

Group 3 (Standard Control): The experimental animals in this group were treated with ascorbic acid (200 mg/kg body weight) as standard drug

Group 4 (Toxicant and Ascorbic acid): Animals in this group were induced with aluminum chloride (34mg/kg body weight) and treated with $200 \mathrm{mg} / \mathrm{kg}$ body weight of ascorbic acid.

Group 5 (Ethanolic extract Massularia acuminate $(50 \mathrm{mg} / \mathrm{kg}$ body weight) and Toxicant): Animals in this group were induced with low dose of ethanolic extract of Massularia acuminata and Toxicant.

Group 6 (Ethanolic extract Massularia acuminate $(100 \mathrm{mg} / \mathrm{kg}$ body weight) and Toxicant). : Animals in this group were induced with high dose of ethanolic extract of Massularia acuminata and Toxicant.

Group 7 (Methanolic extract Massularia acuminate $(50 \mathrm{mg} / \mathrm{kg}$ body weight) and Toxicant). : Animals in this group were induced with low dose of methanolic extract of Massularia acuminata and Toxicant.

Group 8 (Methanolic extract Massularia acuminata $(100 \mathrm{mg} / \mathrm{kg}$ body weight) and Toxicant): Animals in this group were induced with high dose of methanolic extract of Massularia acuminata and Toxicant.

Group 9 (Butanolic extract Massularia acuminate $(50 \mathrm{mg} / \mathrm{kg}$ body weight) and Toxicant): Animals in this group were induced with low dose of butanolic extract of Massularia acuminata and Toxicant.

Group 10 (Butanolic extract Massularia acuminate $(100 \mathrm{mg} / \mathrm{kg}$ body weight) and Toxicant): Animals in this group were induced with high dose of butanolic extract of Massularia acuminata and Toxicant.

\subsection{ANIMAL INDUCTION AND TREATMENT PROCESS}

All experimental animals were initially induced orally with aluminum chloride concentration every morning for 3 weeks as well as treatment with ascorbic acid in the evening daily for 3 weeks. 
ANIMAL SACRIFICE

. The animals were treated for 3 weeks after which they were weighed and were sacrificed using cervical dislocation after they were immobilized using chloroform. The animal's carcasses were treated and disposed properly by burying them into deep ground far from human access.

\section{BLOOD COLLECTION}

. The serum was withdrawn from the animals by injecting the syringe $2-3 \mathrm{~cm}$ deep into the heart of the animals. The blood was ejected into lithium heparin bottles. The samples were preserved in the refrigerator at $-4^{\circ} \mathrm{C}$ for future use.

\section{SUPEROXIDE DISMUTASE}

. The level of SOD activity was quantified according to the method of Misra and Fridovich (1972) and the obtained results is calculated as below:

$$
\text { Increase in absorbance per minute }=\frac{\mathrm{A} 3-\mathrm{A} 0}{2.5}
$$

$\mathrm{A}_{0}=$ absorbance after 30 seconds

$\mathrm{A}_{3}=$ absorbance after 150 seconds

$$
\% \text { inhibition }=\frac{100-100 \times \text { Increase in absorbance for sustrate }}{\text { Increase in absorbance for blank }}
$$

1 unit of SOD activity was given as the amount of SOD necessary to cause $50 \%$ inhibition of the oxidation of adrenaline.

\section{CATALASE}

. The catalase activity was determined according to the direct UV assay method of Aebi (1973) and the results is determined according to the following formular:

$$
\text { Catalase activity }\left(\frac{\text { Units }}{\min }\right)=\frac{[\Delta \mathrm{A} / \min (\text { blank })-\Delta \mathrm{A} / \min (\text { sample })] \times d \times k}{\mathrm{~V} \times 0.0436}
$$

$\mathrm{d}=$ dilution of original sample for catalase reaction

$\mathrm{v}=$ sample volume in catalase reaction in $\mathrm{ml}$

$0.0436=$ extinction coefficient for catalase

$\mathrm{k}=$ total reaction volume in $\mathrm{ml}$

One unit of catalase will decompose 1.0 micromole of hydrogen peroxide to oxygen and water per minute at $\mathrm{pH} 7.0$, at $25^{\circ} \mathrm{C}$.

\section{LIPID PEROXIDATION (MALONDIALDEHYDE (MDA) PRINCIPLE}

. Lipid peroxidation was determined by measuring the formation of thiobarbituric acid reactive substances (TBARS) according to the method of Vashney and Kale (1990). The results obtained is calculated as below: 


$$
\operatorname{MDA}\left(\frac{\text { Units }}{m g} \text { proteins }\right)=\frac{\text { Absorbance } \times \text { volume of mixture }}{\text { E532nm } \times \text { volume of sample } \times \text { mg protein }}
$$

\section{STATISTICAL ANALYSIS}

. The data obtained from the study was analyzed using analysis of variance, while the difference between the means was evaluated by Tukey's Krammer LSD (Least significant difference) test using SPSS version 20 and GraphPrism7.0. The value was represented as Mean \pm standard mean of error (SEM) and values of $\mathrm{P} \leq 0.05$ were considered significant.

\section{RESULTS}

The results of the antioxidant activities (catalase, super oxide dismutase and lipid peroxidation) in the animals' groups after treatment with aluminum chloride, ascorbic acids, and varied extracts of Massularia acuminata in different doses are shown in Table 1. There is significant difference in antioxidants activities in animal groups. Results in Table 1 indicate that there is an elevated rise in lipid peroxidation in the serum of the negative control experimental animals treated with aluminum chloride $\left(177.14 \pm 30.87^{\mathrm{cd}}\right)$ compared with the positive control animals $\left(149.25 \pm 10.36^{\mathrm{bcd}}\right)$; indication of biochemical damage to the toxicant groups. However, there is no significant decrease in lipid peroxidation in ascorbic treated groups $\left(64.00 \pm 6.52^{\mathrm{a}}\right)$ compared to the positive control group $\left(149.25 \pm 10.36^{\mathrm{bcd}}\right)$. Moreover, groups treated with varied solvent extracts of Massularia acuminata after the administration of the toxicant showed varied significant level in MDA with ethanolic extract being the post active potent as shown at reduced level of MDA compared with other extracts and the control. Ethanolic extract have MDA level of $\left(91.56 \pm 28.49^{\mathrm{ab}}\right.$ and $\left.103.53 \pm 34.40^{\mathrm{abc}} 103.53 \pm 34.40^{\mathrm{abc}}\right)$ at lower and upper doses, respectively. They are followed by methanolic extract $\left(151.60 \pm 23.57^{\mathrm{bcd}}\right.$ and $\left.109.40 \pm 12.34^{\text {abc }}\right)$ and finally butanolic extract with $\left(220.94 \pm 16.74^{\text {de }}\right.$ and $\left.264.96 \pm 35.54^{\mathrm{e}}\right)$. The MDA results indicate that butanolic extract may be toxic as it may cause more damage than aluminum chloride, with statistically significant elevated level of MDA higher than aluminum chloride. The same trend is observed in Figure 1. It is evident that the ascorbic acid treated group (Group 3 from the study) has lower level of MDA $\left(138.68 \pm 17.65^{\mathrm{abc}}\right)$ level. This may be evident of the antioxidant protection of the serum offered against lipid peroxidation. The results are statistically significant compared to the MDA level of the control group animals at MDA level of $\left(149.25 \pm 10.36^{\mathrm{bcd}}\right)$. Thus, ascorbic acid may offer strong protection to animals against aluminum chloride toxicities. The MDA level of the aluminum chloride treated group $\left(177.14 \pm 30.87^{\mathrm{cd}}\right)$ is statistically significant and higher than control groups and the ascorbic acid treated group. This is an evidence that ascorbic acid mediates against aluminum chloride toxicity in the study. The effect of Massularia acuminata and ascorbic acid on superoxide dismutase (SOD) activity in the serum of aluminium chloride treated rats is represented in Table 1 and Figure 2, respectively. Results reveal that there is significant increase in SOD enzymes in the serum of the ascorbic acid and higher levels in the solvent extracts intervention groups compared to the positive control group. However, there is an increase in the activity of enzymes among other groups compared to the control groups. Moreover, the groups treated with the aluminum chloride show increase in the activity of the enzyme compared with control groups and plant extracts. This may be attributed to error in handling the animals' groups during laboratory assay. The effect of Massularia acuminata and ascorbic acid on catalase activity in the serum of aluminium chloride treated rats is represented in Figure 3 and Table 1 , respectively. Results show that there is significant decrease in the activity of the enzyme, catalase, in the serum of the group treated with toxicant plus ascorbic acid compared to the positive control 
group. However, there is no significant increase in the activity of the enzyme in group treated with butanolic extract compared to the positive control group and ethanolic extracts. Equally, results in Figure 1 show that animals treated with different doses of butanolic extract show higher oxidative damage and more oxidative stress even more than animals induced aluminum chloride. This may be attributed to laboratory handling. $\mathrm{O}$ the other hand, the group with ascorbic acid combined with toxicant show less presence of malonaldehyde with both ethanol group and $100 \mathrm{mg} / \mathrm{kg}$ body weight of methanolic group. Animals treated with $50 \mathrm{mg} / \mathrm{kg}$ body weight of methanolic extract of Massularia acuminata have similar value of MDA as the control. Results in Figure 2 show that animals treated with $100 \mathrm{mg}$ butanol extract of Massularia acuminata show less activity of superoxide dismutase enzyme, which helps to catalyze superoxide anion into $\mathrm{H}_{2} \mathrm{O}_{2}$ and oxygen, possessing a reduced ability to mob off free radicals generated by aluminium chloride insults. This may be the possible reason for the high malonaldehyde presence in the group. SOD activity presence in the group treated with $50 \mathrm{mg} / \mathrm{kg}$ body weight of butanolic extract is high even above those that show antioxidant properties in Figure 9. However, it shows to cause oxidative stress even with the high SOD presence. Animals in control group - ascorbic acid combined with toxicant group, 50 $\mathrm{mg} / \mathrm{kg}$ body weight of ethanolic extract, 50 and $100 \mathrm{mg} / \mathrm{kg}$ body weight of methanolic extract groups - show similar value to superoxide dismutase. The ascorbic acid and toxicant group also have similar value of superoxide dismutase in Figure 2. The result of catalase activity is as SOD catalyze superoxide anion to $\mathrm{H}_{2} \mathrm{O}_{2}$ and oxygen. Then, $\mathrm{H}_{2} \mathrm{O}_{2}$ is reduced to water and molecular oxygen by catalase. Turnover number is very high but its affinity for $\mathrm{H}_{2} \mathrm{O}_{2}$ is relatively low. Consequently, a certain amount of $\mathrm{H}_{2} \mathrm{O}_{2}$ remains in the cell. There is little of catalase activity detected in those groups (Ascorbic acid combined with $\mathrm{AlCl}_{3}$, both dose of ethanolic extract, both dose of methanolic extract groups) where there is evidence of antioxidant properties (group four to group 8). Control, $\mathrm{AlCl}_{3}$, Ascorbic acid, both dose of butanolic extracts share relatively the same value. The pictorial illustration of Massularia acuminata whole stem bark extract with its leaves in their natural habitat is shown in Figure 4.

\section{DISCUSSION}

According to data and results, there is increase in lipid peroxidation in $\mathrm{AlCl}_{3}$. This study shows that the toxicity and exposure to aluminum chloride may cause damage to animals. Data indicate that serum Malonaldehyde (MDA) significantly $(\mathrm{p}<0.05)$ increased by aluminum chloride $\left(\mathrm{AlCl}_{3}\right)$ treatment. Ascorbic acid caused significant $(\mathrm{p}<0.05)$ decrease in serum TBARS as compared with the control group. The intervention of the treatment of ascorbic acid $0 \mathrm{n} \mathrm{AlCl}_{3}$ caused significant $(\mathrm{p}<0.05)$ decrease of serum malonaldehyde due to treatment with aluminum chloride $\left(\mathrm{AlCl}_{3}\right)$. This means that the presence of ascorbic acid minimized the hazardous effect of aluminum chloride toxicity. Both doses of ethanolic extract dose $(50 \mathrm{mg} / \mathrm{kg}$ and $100 \mathrm{mg} / \mathrm{kg}$ body weight $)$ and group of methanol extract reduced the level of MDA but not as ascorbic acid group. Both doses of methanolic extract of Masssularia acuminata act contrariwise from other extracts in that they show the highest level of malonaldehyde even more than $\mathrm{AlCl}_{3}$. Since malonaldehyde is a marker for oxidative stress, it shows both doses of ethanol. About 50mg of ethanolic extract and $100 \mathrm{mg}$ of methanolic extract have effective antioxidant properties; while the group treated with butanolic extracts of same plant show significant increase in lipid peroxidation, which may be sign of mild toxicity in this group. Thus, animals' exposure of aluminum chloride may cause oxidative stress. There was significant decrease in superoxide dismutase and catalase level in the serum of the experimental animals while the treatment of the animals with aluminum chlorides induced lipid peroxidation significantly in the serum, indicating biochemical damages to the infected animals. Thus, this shows that aluminium 
chloride treatment decreased the activities of antioxidant enzymes necessary to fight reactive oxygen radical species in any biological system. The results revealed that there was an elevated increase in lipid peroxidation as shown by elevated quantity of MDA in the serum of aluminium chloride-treated rats alone compared with the control rats and ascorbic treated rats respectively. This revealed that the natural antioxidant defense mechanism to mob up the free radicals have been compromised in rats induced with aluminium chloride toxicity alone (Pratibha et al., 2004). Increased level of lipid peroxidation has been reported in aluminium chloride induced Wistar rats (Chattopadhyay et al., 1997). Administration of the extracts of Masularia acuminata to the treated rats downsized the level of lipid peroxidation in the serum. This may be attributed to the antioxidants and phytochemicals present in the extracts of the plants which helps to mob off radical species caused by aluminum chloride toxicity. It is, therefore, suggested that Massularia acuminata may contain an active principle which lowers lipid peroxidation. The result of SOD in this study showed an increased activity on both doses of butanolic extracts of Massularia acuminata, followed by ethanolic extracts, while the methanolic extracts at both doses are considered to have a decreased activity of SOD. All data obtained from different extracts of Massularia acuminata have an elevated activity compared with both control rats and ascorbic acids treated rats. Thus, the administration of extracts of Masularia acuminata and ascorbic acids increased the activity of SOD and CAT in aluminum chloride $\left(\mathrm{AlCl}_{3}\right)$ treated rats relative to the toxicant group. The results revealed that Masularia acuminata extracts may possess an antioxidant activity which could exert a beneficial action against any pathology alteration caused by the biochemical insults due to the treatment of aluminium chloride. The results of superoxide dismutase (SOD) assay test in this study show that the control group, ascorbic acid combined with aluminum chloride $\left(\mathrm{AlCl}_{3}\right)$ group, $50 \mathrm{mg} / \mathrm{kg}$ body weight of ethanolic extract. Both doses methanolic extract groups have the same comparative value of SOD. The group treated with toxicant (aluminum chloride) and ascorbic group has similar relative value. The group treated with $50 \mathrm{mg} / \mathrm{kg}$ body weight of butanolic extract shows the highest value of superoxide dismutase activity follow closely by $100 \mathrm{mg} / \mathrm{kg}$ of ethanolic extract group. The group treated with $100 \mathrm{mg} / \mathrm{kg}$ body weight of butanolic group shows less activity value of the superoxide dismutase (SOD). The result of catalase shows that the level and activity of the enzyme in the groups treated with ascorbic acid and aluminum chloride. Both doses of ethanolic and methanolic extracts groups show significant decrease in the activity of the enzyme lower than control group. This may relate to increased exposure of the toxicity of aluminum chloride which depletes the synthesis of these classical antioxidant necessary to mob the system of all foreign substances via-a-viz the aluminium chloride toxicity. Equally, the results of ascorbic acid and different doses of butanolic extracts of Massularia acuminata show approximately increased degrees of catalase enzyme which was the highest value of the catalase enzyme in the study.

\section{CONCLUSIONS:}

In conclusion, both $50 \mathrm{mg} / \mathrm{kg}$ and $100 \mathrm{mg} / \mathrm{kg}$ doses of ethanolic extract and $100 \mathrm{mg} / \mathrm{kg}$ of methanolic extracts of Massularia acuminata show higher antioxidant activity which cause significant reduction in the levels of lipid peroxidation (malonaldehyde) in animals. This is an important marker in lipid peroxidation caused by oxidative stress. On the other hand, the same level of superoxide dismutase (SOD) and catalase (except for $100 \mathrm{mg} / \mathrm{kg}$ body weight of ethanolic extract) is shown with level of ascorbic acid group treated with aluminum chloride compound. However, $50 \mathrm{mg} / \mathrm{kg}$ body weight and $100 \mathrm{mg} / \mathrm{kg}$ body weight of butanolic extract of Massularia acuminata show that they cause oxidative stress in that they increase malonaldehyde (MDA). Hence, the ethanolic and methanolic extract of Massularia acuminata can serve as potential antioxidant compounds in the treatment of 
oxidative stress associated with aluminum chloride toxicity. Therefore, both extracts of methanolic and ethanolic of Massularia acuminata may supplement the use of ascorbic acid which serves as an intervention against any oxidative damage due to aluminum chloride toxicities. Thus, Massularia acuminata may possess antioxidant enzymes which may act in similar manner like superoxide dismutase and catalase against any oxidative stress. It may, therefore, be used to protect the body against any pathological attacks by free radical and oxidative insults from any xenobiotics.

\section{SUPPLEMENTARY MATERIALS:}

Table 1. Antioxidant Effects of Massularia acuminata Extracts and Ascorbic Acids on Some Antioxidant Marker Enzymes in Experimental Animals.

\begin{tabular}{|c|c|c|c|}
\hline & $\begin{array}{l}\text { MDA } \\
(\mathrm{u} / \mathrm{l})\end{array}$ & $\begin{array}{l}\text { SOD } \\
(\mathrm{u} / \mathrm{ml})\end{array}$ & $\begin{array}{c}\text { CATALASE } \\
\left(\mu \mathrm{molH}{ }_{2} \mathrm{O}_{2}\right. \\
\text { decomposed/min })\end{array}$ \\
\hline Control & $149.25 \pm 10.36^{\text {bcd }}$ & $250.00 \pm 48.11^{\mathrm{ab}}$ & $53.07 \pm 9.68^{b}$ \\
\hline Aluminum chloride $\left(\mathrm{AlCl}_{3}\right)$ & $177.14 \pm 30.87^{\mathrm{cd}}$ & $333.33 \pm 0.00^{\mathrm{abc}}$ & $52.60 \pm 6.53^{b}$ \\
\hline Ascorbic acid (200 mg) & $138.68 \pm 17.65^{\mathrm{abc}}$ & $333.33 \pm 0.00^{\mathrm{abc}}$ & $50.07 \pm 4.79^{b}$ \\
\hline Ascorbic acid (200 mg) + $\mathrm{AlCl}_{3}(34 \mathrm{mg})$ & $64.00 \pm 6.52^{\mathrm{a}}$ & $305.56 \pm 27.78^{\mathrm{ab}}$ & $3.28 \pm 0.14^{\mathrm{a}}$ \\
\hline Ethanolic extract (50 mg) + $\mathrm{AlCl}_{3}(34 \mathrm{mg})$ & $91.56 \pm 28.49^{\mathrm{ab}}$ & $305.56 \pm 73.49^{\mathrm{ab}}$ & $4.44 \pm 1.19^{\mathrm{a}}$ \\
\hline Ethanolic extract $(100 \mathrm{mg})+\mathrm{AlCl}_{3}(34 \mathrm{mg})$ & $103.53 \pm 34.40^{\mathrm{abc}}$ & $361.11 \pm 27.78^{\mathrm{bc}}$ & $7.04 \pm 1.30^{\mathrm{a}}$ \\
\hline Methanolic extract $(50 \mathrm{mg})+\mathrm{AlCl}_{3}(34 \mathrm{mg})$ & $151.60 \pm 23.57^{\text {bcd }}$ & $305.56 \pm 27.78^{\mathrm{ab}}$ & $1.61 \pm 0.67^{\mathrm{a}}$ \\
\hline Methanolic extract $(100 \mathrm{mg})+\mathrm{AlCl}_{3}(34 \mathrm{mg})$ & $109.40 \pm 12.34^{\mathrm{abc}}$ & $305.56 \pm 27.78^{\mathrm{ab}}$ & $3.01 \pm 0.65^{\mathrm{a}}$ \\
\hline Butanolic extract $(50 \mathrm{mg})+\mathrm{AlCl}_{3}(34 \mathrm{mg})$ & $220.94 \pm 16.74^{\mathrm{de}}$ & $444.44 \pm 27.78^{c}$ & $56.76 \pm 8.10^{b}$ \\
\hline Butanolic extract $(100 \mathrm{mg})+\mathrm{AlCl}_{3}(34 \mathrm{mg})$ & $264.96 \pm 35.54^{\mathrm{e}}$ & $222.22 \pm 55.56^{\mathrm{a}}$ & $56.56 \pm 10.14^{\mathrm{b}}$ \\
\hline
\end{tabular}

Data are expressed as Mean \pm SEM for each group. One-way ANOVA was used to compare variables between groups, while Post hoc was used to differentiate between variables in a group. Different alphabets are used to indicate statistical significance at $(\mathrm{p} \leq 0.05)$ compared to normal control and standard control. Values with the same alphabet show no significance difference. 


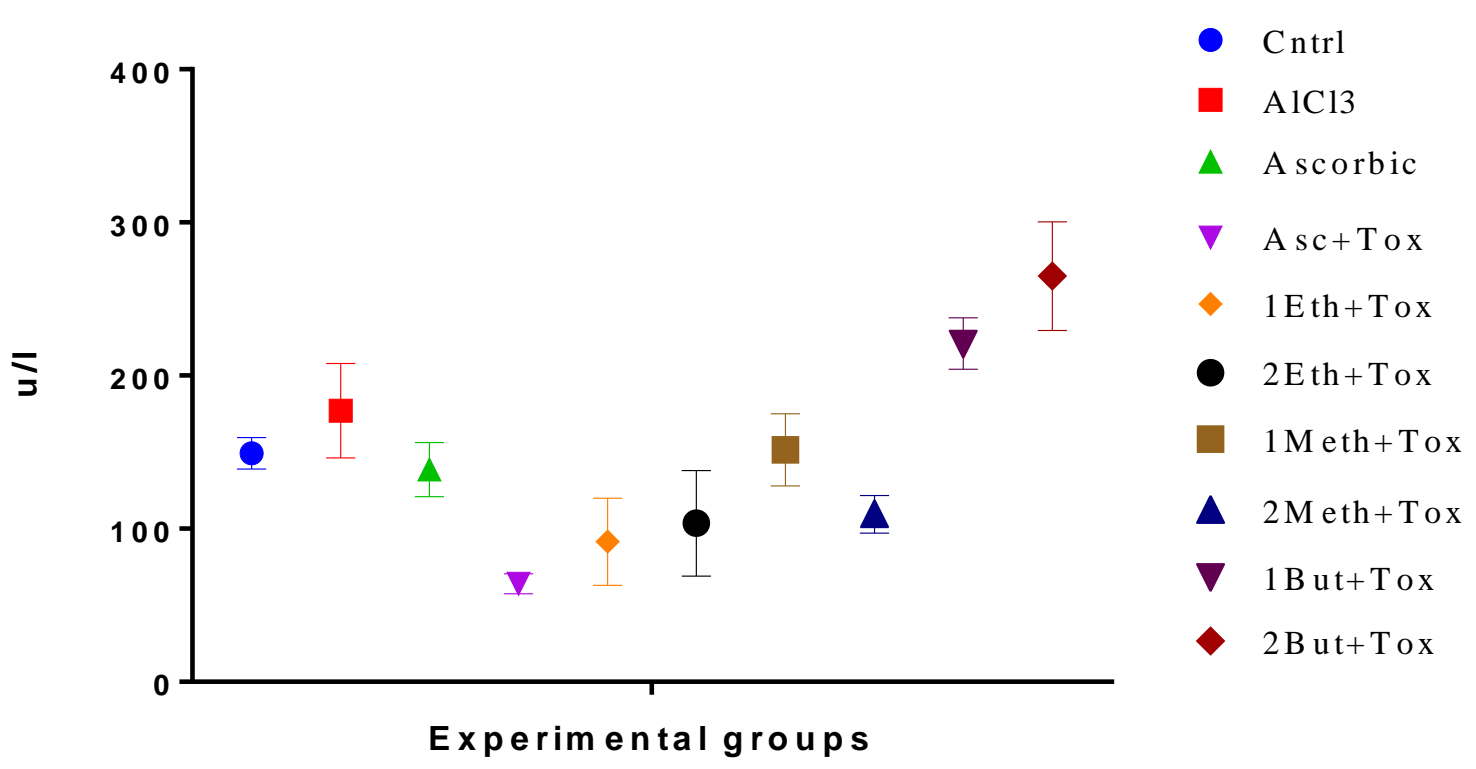

Figure 1. Effects of Massularia acuminata Extracts on Malonaldehyde (MDA) level Lipid Peroxidation in Experimental Wistar Rats.

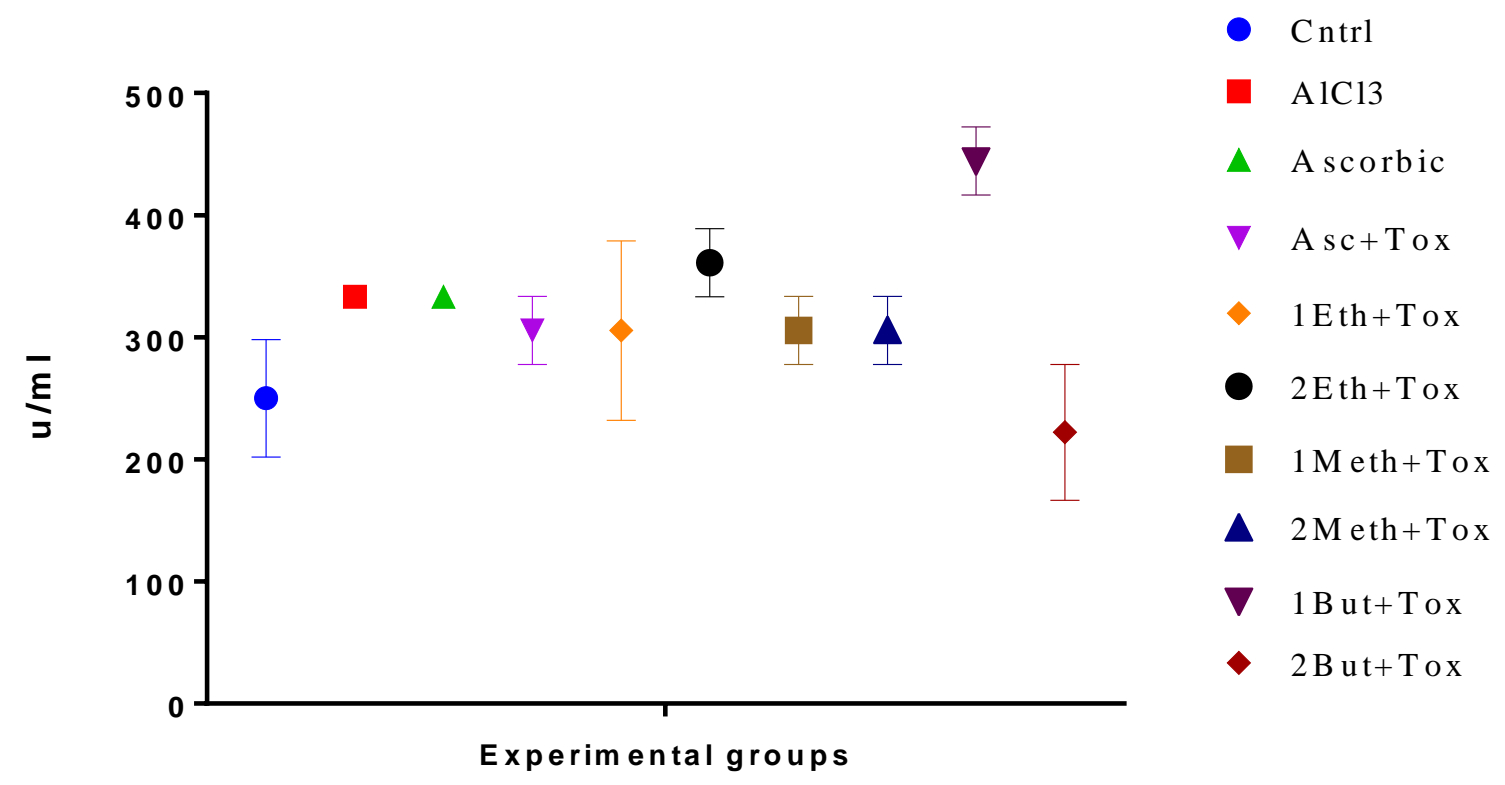

Figure 2. Effects of Massularia Acuminata Extracts on Superoxide Dismutase (SOD) in Experimental Wistar Rats. 


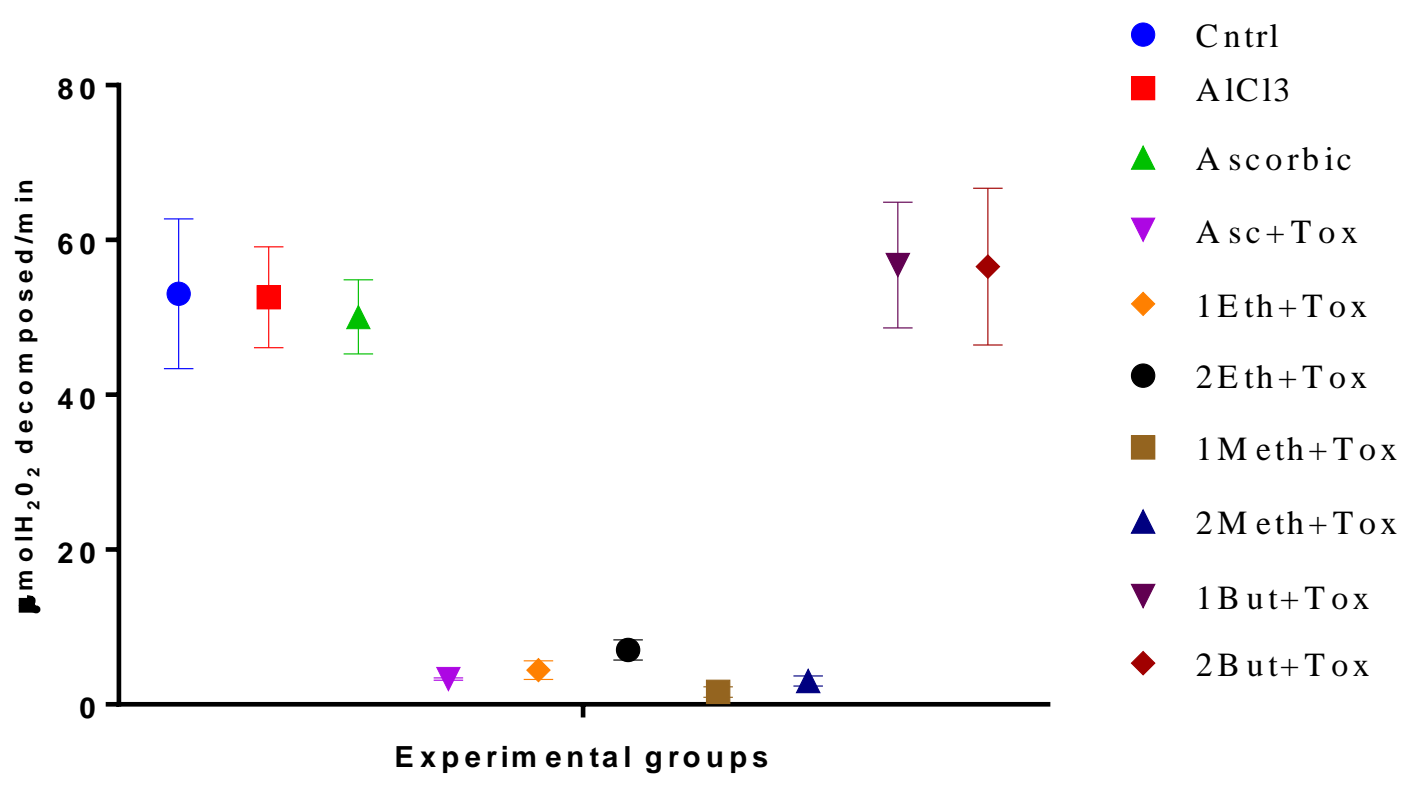

Figure 3. Effects of Massularia Acuminata Extracts and Ascorbic Acid on Catalase (CAT) Activities in Experimental Wistar Rats.

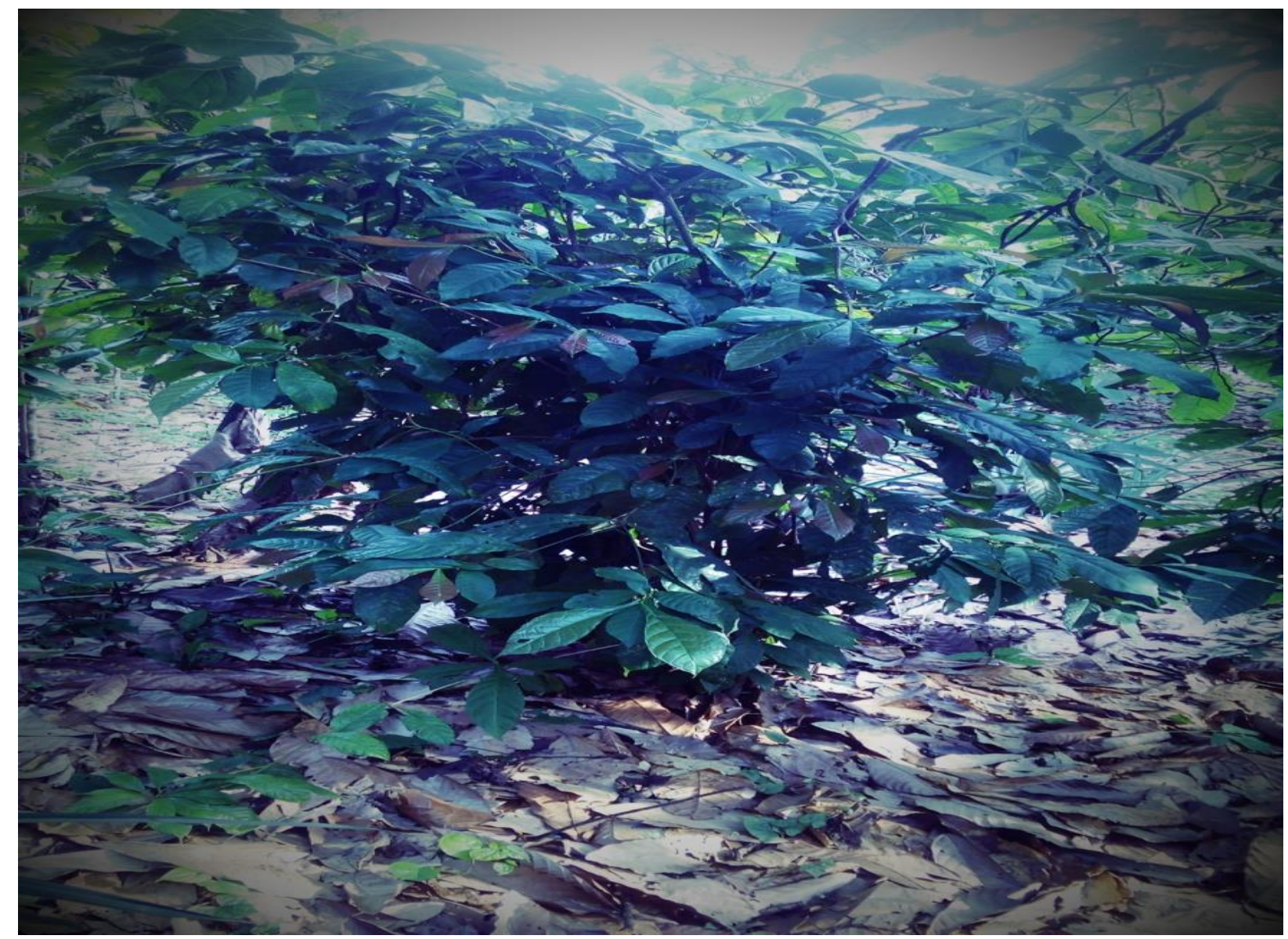

Figure 4. Massularia Acuminata Stem Bark and Its Flower in its Natural Habitat 
Acknowledgements: The authors wish to acknowledge the contributions and support of all their undergraduate students Odolofin, Victor Emmanuel., Aminu, Azeezat Goodluck, Akinyomi Adebayo Samuel. and Preye Faith. They participated and displayed discipline with strong commitment towards the success of this research work throughout all the phases of this research.

\section{Authors' Contributions}

This work was carried with collaboration of different authors from different department and universities. Author Bakare Oluwafemi Shittu did the experimental background proposal design of the study. Owoloye Afolabi carried out the statistical analysis of the experimental results. Bakare Oluwafemi Shittu and Owoloye Afolabi also jointly collate the protocols for the experimental assays for the study while Bakare Oluwafemi Shittu wrote the first draft of the manuscript. Adedugbe Omowunmi Funke and Owoloye Afolabi managed the analyses of the study and managed the literature search and proof reading. All authors read contributed to the writing up and approve the manuscript.

Conflicts of Interest: We declare that there are neither conflicts of interests nor funding sponsor in executing this research paper.

\section{REFERENCES}

[1] Abbasali, K., Zhila, T. \& Farshad, N. (2005). Development toxicity of aluminium from high doses of $\mathrm{AlCl}_{3}$ in mice. The Journal of Applied Research. 5, 575-579

[2] Aderinokun, Lawoyin, J. O. \& Onyeaso, C.O. (1999). Effect of two common Nigerian chewing sticks on Gingival health and oral hygiene. Odonto-Stomatologie Tropicale. 22(87), 13-18.

[3] Aebi, H. (1973). In methods of Enzymatic Analysis, Bergmeyer, H.U., Ed., Verlag Chemie Weinheim. Pp. 673-684.

[4] Aguirre, R. \& May, J.M. (2008). Inflammation in the vascular bed: Importance of vitamin C. Pharmacology and Therapeutics. 119, 96-103.

[5] Aitken, R.J. and Roman, S.D. (2008). Antioxidant system and oxidative stress in the testes. Advances in Experimental Medicine and Biology. 636(1), 154-171.

[6] Aladesanmi, A. J., Iwalewa, E.O., Akinkunmi, E. O., Adebajo, A.C., Taiwo, B.J., Olorunmola, F.O. \& Lamikanra, A. (2007). Antimicrobial and antioxidant activities of some Nigerian medicinal plants. African Journal of Traditional Complementary and Alternative Medicines. 4(2), 173-184.

[7] Anderson, D., Phillips, B. J., Yu, T., Edwards, A.J., Ayesh, R. \& Butterworth, K.R. (1997). The effect of vitamin $\mathrm{C}$ supplementation on biomarkers of oxygen radical generated damage in human volunteers with low or high cholesterol levels. Environmental Molecular Mutagens. 30, 161-174

[8] Anthony M. U., Adebimpe, A.O. \& Ekpo, K.E. (2009). Antioxidant potential of the Young Leave Methanolic Extract of Magnifera Indica in Alloxan Induced Diabetic Rat. Pakistan Journal of Nutrition. $8(6), 716-720$

[9] Arrigoni, O. \& De Tullio, M.C. (2002). Ascorbic acid: much more than just an antioxidant. Biochimica et Biophysica Acta (BBA)- General Subjects. 1569(1-3), 1-9 
[10] Arumugam, K., Onorine, M.S., Palaniandy, G., Dasal, V., Balaji, G. \& Venugopal, R. (2014). Influence of aluminium chloride on antioxidant system in the testis and epididymis of rats. Iranian journal of Toxicology. 8(24), 991-997

[11] Banik, G. N., Chakraborty, I. \& Mukhopadhyay, P.K., (2014). Ameliorative effects of $\alpha$-tocopherol and ascorbic acid on the accessory reproductive glands of adults male rats in arsenic toxicity. International Journal of Pharmaceutical Science Review Research. 26, 282

[12] Burkill, H. M. (1997). Useful plants of West Tropica Africa. Royal Botanic Gardens, Kew, 4, 969

[13] Carr, A.C. \& Frei, B. (1999). Toward a new recommended dietary allowance for vitamin C based on antioxidant and health effects in humans. American Journal of Clinical Nutrients. 69(6), 1086-1107

[14] Chattopadhyay, S., Ramanathan, M., Das, J. \& Bhattacharya, S.K. (1997). Animal models in experimental diabetes mellitus. Indian Journal of Experimental Biology. 35, 1141-1145

[15] El-Demerdash, F.M. (2004). Antioxidant effects of vitamin E and selenium on lipid peroxidation, enzyme activities and biochemical parameters in rats exposed to aluminium. Journal of Trace Elements in Medicine and Biology. 18(1), 113-121

[16] El-Demerdash, F.M., Yousef, M.I., Kamel, K.I. \& El-Guendi, M.I. (2007). An in vitro study on reproductive toxicity of aluminium chloride on rabbit sperm: The protective role of some antioxidants. Elsevier Journal of Toxicology. 239, 213-223

[17] Eryilmaz, P.F. (2014). Effects of exogenously applied ascorbic acid on red cabbage cotyledons subjected to copper excess. Fresenius Environmental Bulletin. 23, 15-19

[18] Exley, C. (1998). Does antiperspirant use increase the risk of aluminium-related disease, including Alzheimer's disease? Mol. Med. Today. 4, 107-109

[19] Hacisevki, A. (2009). An overview of ascorbic acid Biochemistry. Journal of Faculty of Pharmacy Ankara. 38(3), 233-255

[20] Jeyekumar, S.M., Naini, N. \& Menon, V.P. (1999). Antioxidant activity of ginger (Zingiber officienale rocs) un rats fed a high fed a high fat diet. Medical Science Research. 27, 341-344.

[21] Jomova, K. \& Valko, M. (2011). Advance in metal-induced oxidative stress and human disease. Toxicology, 283(2-3), 65-87

[22] Kumar, V. \& Gill, K.D. (2009). Aluminium neurotoxicity: Neurobehavioural and oxidative aspects. Archives of Toxicology. 83(11), 965-978

[23] Mahdi, A.A., Tripathi, S., Neerja, J. \& Hasan, M. (2006). Aluminium mediated oxidative stress: Possible relationship to cognitive impairment of alzheimer's Type. Annals of Neurosciences. 13(1), 18-24

[24] Mahieu, S., DelCarmen, C.M., Gonzalez, M., Millen, N. \& Ellias, M.M. (2000). Aluminium toxicity. Hematological effects. Toxicolgical Letters. 111(3), 235-242

[25] Mansour, S., Shenkin, A. \& Roberts, N.B. (2006). Aluminium-induced injury to kidney proximal tubular cells: Effects on markers of oxidative damage. Journal of Trace Elements in Medicine and Biology. 19(4), 267-273

[26] Mistra, H. P. \& Fridovich, I. (1972). The role of superoxide anion in the autoxidation of Epinephrine and a simple assay for superoxide dismutase. Journal of Biological Chemistry. 247, 3170-3175.

[27] Mondal, R., Biswas, S., Chatterjee, A., Misra, R., Mukhopadhyay, A., Bhadra, R. K. \& Mukhopadhyay, P.K. (2016). Protection against arsenic-induced hematological and hepatic anomalies by supplementation of vitamin C and vitamin E in adult male rats. Journal of Basic Clinical Physiology Pharmacology. 27(6), 1-10 
[28] Mukhopadhyay, P. K., Dey, A., Mukherjee, S. \& Pradhan, N. K. (2013). The effects of co-administration of alpha-tocopherol and ascorbic acid on arsenic trioxide-induced testicular toxicity in adult rats. Journal of Basic Clinical Physiology and Pharmacology. 24, 245-253

[29] Northrop-Clewes, C.A. \& Thurnham, D.I. (2007). Monitoring micronutrients in cigarette smokers. Clin. Chem. Acta, 377(1-2), 14-38

[30] Osinska, E. \& Kusiak, A. (2004). Aluminum hemotoxicity mechanisms. Annales Universitatis Mariae Curie-Skłodowska. Sectio D: Medicina. 59(1), 411-416

[31] Qitu, M.A., Rengel, Z. \& Kuo, J. (2002). Aluminium toxicity in rye (Secale cereale): root growth and dynamics of $\mathrm{Ca}^{2+}$ in intact root Tipps. Annals of Botany. 89(2), 241

[32] Pratibha, K., Usha, A. \& Rajni, A. (2004). Serum adenosine deaminase51-nucleotidase and malondialdehyde in acute infesctive hepatitis. Indian Journal of Clinical Biochemistry. 19, 128-131

[33] Rotimi, V., Laughon, B. E., Bartlett, J. G. \& Mosadomi, H. A. (1988). Activities of Nigerian chewing stick extracts against Bacteroides gingivalis and Bacteroides melaninogenicus. Antimicrobial Agents and Chemotherapy. 32(4), 598-600.

[34] Sauer, M., Branduardi, P., Valli, M. \& Porro, D. (2004). Production of L-ascorbic by metabolically engineered Saccraromyces cerevisiae and Zygosaccharomyces bailii. Applied and Environmental Microbiology. 70(10), 6086-6091

[35] Taiwo, O., Xu, H.X. \& Lee, S.F. (1999). Antibacterial activities of extracts from Nigerian chewing sticks. Phototherapy Research. 13, 675-679

[36] Turner, T.T. \& Lysiak, J.L. (2008). Oxidative stress: A common factor in testicular dysfunctions. Journal of Andrology. 29, 488-498

[37] Vashney, R. \& Kale, R.K. (1990). Effects of calmodulin antagonist. International Journal of Radiation Biology. 58, 733-743

[38] Verstraeten, S. V., Aimo, L. \& Oteiza, P.I. (2008). Aluminium and lead: Molecular mechanism of brain toxicity. Archives of Toxicology. 82(11), 789-802.

[39] Ward, R.J., Zhang, Y., \& Crichton, R.R. (2001). Aluminium toxicity and iron homeostasis. Journal of inorganic Biochemistry. 87(1-2), 9-14.

[40] Yakubu, M.T., Nwodo, O.F.C., Imo, C. \& Ogwoni, H.A. (2008). Spermatogenic and Haematological effects of Aqueous and Ethanolic Extracts of Hymenocardia acida Stem Bark on Aluminium-Induced Toxicity in Male Wistar Rats. Insights in Biomedicine. 2(1), 1-5.

[41] Yokel, R.A. (2000). The toxicology of aluminium in the brain: A review. Neurotoxicology. 21(5), 813-828.

[42] Yousef, M.I. \& Salama, A.F. (2009). Propolis protection from reproductive toxicity caused by aluminium chloride in male rats. Food and Chemical Toxicology. 47, 1168-1175.

[43] Yousef, M.I., El-Morsy, A.M.A. \& Hassan, M.E. (2005). Aluminum-induced deterioration in reproductive performance and seminal plasma biochemistry of male rabbits: Protective role of ascorbic acid. Toxicology. 215, 97-107 